\title{
Electrophoretic Characterization of Gynoecious and Monoecious Cucumber (Cucumis sativus L.) Genotypes Based on Seed Protein Profiles
}

\author{
Shailaja Punetha ${ }^{1 *}$, Basavaraj Makanur ${ }^{2}$, Deepali Tewari ${ }^{1}$ and Parul Punetha ${ }^{3}$ \\ ${ }^{1}$ Department of Vegetable Science, ${ }^{2}$ Department of Seed Science and Technology, \\ ${ }^{3}$ Department of Floriculture and Landscape Architecture, G.B. Pant University of Agriculture \\ and Technology, Pantnagar-263145, Uttarakhand, India \\ *Corresponding author
}

\section{A B S T R A C T}

\section{Keywords}

Cucumber, Protein profiling, SDS-PAGE, Germplasm, Genetic diversity, Electrophoresis

Article Info

Accepted:

24 September 2018

Available Online:

10 October 2018
Thirteen (Three gynoecious and ten monoecious) germplasm lines of cucumber (Cucumber sativus L.) were characterized by sodium dodecyl sulphate polyacrylamide vertical slab gel electrophoresis (SDS-PAGE). The seed protein could be resolved into total 11 bands distributed in 4 zones i.e. A, B, C and D. Zone A was divided into 5 subzones and 5 bands, zone B has 1 band $\mathrm{C}$ has 5 and zone D included 5 bands. Similarity index value ranged from $62 \%$ to $100 \%$ among all the genotypes. Pgyn-1 showed least similarity $68 \%$ with other genotypes. It was observed that all the gynoecious genotypes were dissimilar to monoecious genotypes. It was possible through seed protein profiles to distinguished morphologically similar genotypes. Hence, seed protein profiles proved useful in identifying gynoecious and monoecious lines of cucumber.

\section{Introduction}

Cucumber (Cucumis sativus L.) is one of the most popular vegetables of the family Cucurbitaceae. It is an important summer vegetable crop of tropical India and is an important vegetable crop in terms of utility as well as foreign exchange. Cucurbitaceae, the gourd family, is one of the largest families of flowering plant, comprising of over 940 species and about 122 genera distributed in tropical and sub-tropical regions of the world (Shaefer and Renner, 2011). Among
Cucurbits, bottle gourd, bitter gourd, cucumber, ivy gourd, ridge and snake gourd, melons etc. demonstrate exuberant ethnomedicinal and agronomical chattels and are consumed as vegetal crop by humankind (Jeffrey, 2005). A wide range of genetic variability is available in cucumber. Releasing large number of varieties and increasing morphological similarities between them, it would make bit of confusion among plant breeders and producers. So it is necessary to differentiate one cultivar form the other cultivars. 
Varietal characterization based on morphological data is becoming difficult because these morphological traits are highly influenced by environment. Morphologies reflect not only genetic constitution of cultivars, but also interaction of the genotype with the environment. Due to the Genotype X Environment effects, it is inappropriate to discriminate ambiguity among similar morphological expressions. Descriptions based on morphologies are fundamentally flawed in their ability to provide reliable information for calculation of genetic distance or validation of pedigrees. Establishing the identity of a variety through registration is critical from the point of Plant Variety Protection (PVP) as well as seed multiplication and subsequent handling. According to Protection of Plant Varieties and Farmer's Rights Act 2001 (PPV\&FR) of India, the varieties need to be characterized in detail for establishing their distinctness, uniformity and stability (DUS) before they are introduced in seed multiplication chain.

One of the biochemical methods more extensively used for taxonomic purposes has been the electrophoretic analysis of the proteins found in seeds and storage organs (Ladizinsky and Hymowitz, 1979), electrophoresis analysis is also used to study molecular systematic for identification of genotypes based on proteins and this technique of Sodium Dodecyl Sulphate Polyacrylamide Gel Electrophoresis (SDSPAGE) is commonly used for separation of seed storage proteins (Ullah et al., 2010). Therefore, isozymes or biochemical markers are different in enzymes that are detected by electrophoresis and specific staining. Biochemical markers are the protein produced by gene expression. Such protein profile has been extensively exploited for taxonomic and evolutionary studies. Knowledge of genetic variation is a useful tool in genebank management, helping in the establishment of core collections, facilitating efficient sampling and utilization of germplasm (identifying and/or eliminating duplicates in the gene stock), and selection of desirable genotypes to be used in breeding programs. Characterization of germplasm using biochemical techniques (storage proteins and isozymes) has received a great attention in the last decades. This attention was attributed to the increased recognition of germplasm resources in crop plants improvement. Sodium dodecyl sulphate polyacrylamide gel electrophoresis (SDS/PAGE) is among the biochemical technique that is widely used due to its simplicity and effectiveness for describing the genetic structure of the accessions of wild plant species. Protein electrophoresis is considered a reliable, practical and reproducible method because seed storage proteins are the third hand copy of genomic DNA and largely independent of environmental fluctuations (Sammour, 1987; Javaid et al., 2004; Iqbal et al., 2005).

In 1986, ISTA adopted a standard reference method of PAGE for identification of varieties of wheat and barley into its international rules, involving separation of gliadin from wheat and hordein from barley (ISTA, 1986). UPOV has recommended SDS-PAGE for analysis of high molecular weight glutenins in wheat (Anonymous, 1994a) and hordeins in barley (Anonymous, 1994b). Though for cucumber, molecular markers like SSRs and SNPs are now contemplated for profiling of the varieties; SDS-PAGE profiling is relatively simple, inexpensive, does not need elaborate laboratory equipment or other additional paraphernalia and can be adopted by field laboratories of rice workers for varietal identification and characterization.

Seed protein and isozyme variants that migrate different rates have been extensively used as a marker of characterization of cucurbits (Dane, 1983; Knerr et al., 1995). Seed protein has the 
advantage of being scorable, from inviable organ or tissues and the electrophoretic protocols for bulk protein assay are generally simpler than for isozymes (Gepts, 1990). Electrophoresis of seed or seedling extracts followed by appropriate protein or activity stains has been suggested as a possible method for distinguishing cultivars (Larsen and Benson, 1970; Wilkinson and Beard, 1972). These techniques are all based on the concept that each cultivar is distinct and relatively homogeneous at the genetic level. Thus by screening enough loci one should be able to uniquely define each cultivar. Soluble proteins of seeds are the physiologically active constituents, which constitute bulk of enzymes involved in plant metabolism and are responsible for the nutritional and technological property of plant (Johari et al., 1977). Soluble proteins being primary gene products provide a valuable tool of making genetic system and hence, different methods of electrophoresis are used in chemo taxonomical studies of plant species (Ahl et al., 1982 and Agrawal, 1985). This technique is least influenced by environment and is used as "Fingerprint" to identify genotypes (Smith and Smith, 1992). Therefore, the following experiment was carried out to characterize the thirteen (Three gynoecious and ten monoecious) germplasm lines of cucumber through SDS-PAGE seed protein profiles.

\section{Materials and Methods}

\section{Plant material}

Cucumber seeds were collected from Department of Vegetable Science, GBPUA\&T, Pantnagar, India. Thirteen genotypes of Cucumis sativus L. were electrophoretically characterized using SDSPAGE at the Biotech Laboratory of Department of Genetics and Plant Breeding. Genotypes are enlisted in the following Table 1.

\section{SDS-PAGE}

\section{Protein extraction and purification}

Collected seeds of thirteen genotypes viz., Pgyn-1, Pgyn-4, Pgyn-5, PCUC-8, Pant Khira1, PCUC-83, PCUC-126, PCUC-208, PCUC15, PCUC-25, PCUC-35, US-832, Punjab Naveen were crushed and grounded with the help of mortar and pestle using CTAB method (Doyle and Doyle, 1987). The seed flour was taken in to a $10 \mathrm{ml}$ test tube. A volume of $5 \mathrm{ml}$ of chloroform, methanol and acetone mixture (2:1:1) was added and mixed well by vortexing. Then the samples were kept at room temperature for overnight. After centrifuging the samples the solvent was removed and taken the defatted seed powder was placed in $1.5 \mathrm{ml}$ eppendorf tubes. Then the protein extraction buffer $(0.6 \mathrm{M}$ Tris HCL buffer-pH 6.8 mixed SDS and $\beta$ mercaptoethanol) was added. Bromophenol blue was added to extraction buffer as a dye to point out the movement of protein in the gel. All these chemicals were mixed together then the solution was purified and homogenated. The samples were thoroughly vortexed and centrifuged at $12,000 \mathrm{rpm}$ for 10 minutes at room temperature (RT). After centrifuging the samples, the crude protein recovered as clear supernatant on the top of the tube. Then supernatant were transferred into new $1.5 \mathrm{ml}$ Eppendorf tubes and stored at $-20{ }^{0} \mathrm{C}$ until gel electrophoresis. Proteins profiling of samples was performed using SDS- polyacrylamide gels as described by Laemmli (1970) protocol.

\section{Electrophoresis}

Crude protein samples were directly analyzed by SDS-PAGE using $12.0 \%$ polyacrylamide as resolving gel and 4.5\% stacking gel. $20 \mu \mathrm{g}$ protein samples were loaded with the help of micropipette into the wells of the stacking gel. Electrophoresis was carried out at $20 \mathrm{~V}$ for staking gel and $100 \mathrm{~V}$ for as resolving gel, 
until the bromophenol blue (BPB) reached to the bottom of gel plate.

\section{Staining}

After completion of electrophoresis, the gels were placed in fixing solution (15\% TCA) in staining box for overnight. After decanting, the fixing solution, pored the $2.0 \%(\mathrm{w} / \mathrm{v})$ coomassie brilliant blue (CBB) R250 in box.

\section{De-staining}

When the staining procedure was completed, then the gel was de-stained by washing with a solutioncontaining acetic acid, methanol and water in the ratio of $5: 20: 75(\mathrm{v} / \mathrm{v})$, so that the blue color of the coomassie brilliant blue (CBB) $\mathrm{R}$ disappears and the electrophoresis band on gels clearly visible.

\section{Gel analysis and data processing}

The protein bands were scored as 0 for absence or 1 for presence for polymorphism. The Jaccard's similarity index was calculated using NTSYS-pc version 2.02e (Applied BioStatistics, Inc., Setauket, NY, USA) package to compute pair wise Jaccard's similarity coefficients and this similarity matrix was used in cluster analysis using an unweighted pair group method with arithmetic averages (UPGMA) and sequential, agglomerative, hierarchical and nested (SAHN) clusteringalgorithm to obtain a dendrogram.

\section{Results and Discussion}

\section{Protein profile pattern of cucumber genotypes by SDS-PAGE}

Although uniformity and uniqueness of the seed protein profiles are typical of many groups of the plants, variation in the number of bands and their position in the profile have been reported especially where a good number of accessions were examined. Seed protein variants have been observed to be the most widely used biochemical genetic markers during the last quarter century. Its success depends on the polymorphism of seed proteins and the fact that these proteins represent primary gene products and are largely unaffected by the environmental interactions (Smith and Smith, 1992). The seed protein profile of three gynoecious and ten monoecious cucumber genotypes was carried out using SDS-PAGE for biochemical characterization. The protein profile of banding pattern is given in Figure 1.

The profile was divided into four zones A, B, $\mathrm{C}$ and $\mathrm{D}$ each zone was allocated with a number of protein bands or subzones. Zone A was nearest to origin (gel wells) and comprised protein bands of high molecular weight while zone D was the farthest from origin and thus had protein bands of low molecular weight. A standard medium range protein molecular weight marker of known molecular weight $(14,300 \mathrm{kDa}$ to $97,400 \mathrm{kDa})$ was used along with samples. For genotype discrimination, the presence and absence of protein bands was the criteria selected for characterization.

Each zone was further subdivided into a number of bands (Fig. 1). Zone A representing the heaviest molecular weight protein was subdivided into three intense to light and sharp band of subzones A1, A2, A3,A4 and A5. Zone $\mathrm{B}$ was representing a dark band. Zone $\mathrm{C}$ was representing thick and sharp bands of subzones C1, C2, C3, C4 and C5. Zone D was representing dark and light band and divided in five subzones D1, D2, D3, D4 and D5.

Subzone A1 band was present in only one genotype Pgyn-1 and absent in all other 12 genotypes. Subzone A2 was absent in Pgyn-1 and present in remaining al 12 parents (Pgyn4, Pgyn-5, PCUC-8, Pant Khira-1, US-832, 
PCUC-15, PCUC-25, PCUC-35, PCUC-83, PCUC-126, PCUC-208, and Punjab Naveen). Subzone A3 showed in 10 monoecious genotypes i.e. PCUC-8, Pant Khira-1, US-832, PCUC-15, PCUC-25, PCUC-35, PCUC-83, PCUC-126, PCUC-208, and Punjab Naveen. Subzone A4 was presents thick band in all 10 monoecious parents i.e. PCUC-8, Pant Khira1, US-832, PCUC-15, PCUC-25, PCUC-35, PCUC-83, PCUC-126, PCUC-208, and Punjab Naveen. Subzone A5 was present only in Pgyn-1, Pgyn-4 and Pgyn-5.

Subzone C1 was present only in PCUC-8. The subzone $\mathrm{C} 2$ was present in parents in seven genotypes, Pant Khira-1, PCUC-15, PCUC25, PCUC-35, PCUC-83, PCUC-208, and Punjab Naveen. Subzone C3 was present in Pgyn-1 and Pgyn-4 only. Subzone D2 was present only in Pgyn-1. Subzone D3 was present only in PCUC-25 and Punjab Naveen. Subzone D4 was present in Pgyn-1, Pgyn-4,
US-832, PCUC-126 and PCUC-208. Subzone B1, C4, C5, D1 and D5 bands were present in all gynoecious and monoecious genotypes under study.

Zone A1 and D2 were only present in Pgyn-1 and absent in all others bands. Zone A3 was present in monoecious genotypes and absent in gynoecious genotypes. Zone A2 was present in all monoecious genotypes along with two gynoecious genotype Pgyn-4 and Pgyn-5. Maximum ten bands were found in parents Pgyn-1, PCUC-15, PCUC-25 PCUC208, Punjab Naveen and rest of genotypes showed nine bands in different locations. The banding pattern of these forty varieties was uniform and was not affected by the repeated electrophoretic runs. Though no unique band was observed specific for a variety, all the varieties studied exhibited unique banding patterns (Fig. 1).

Fig.1 Protein profile of gynoecious and monoecious cucumber genotypes

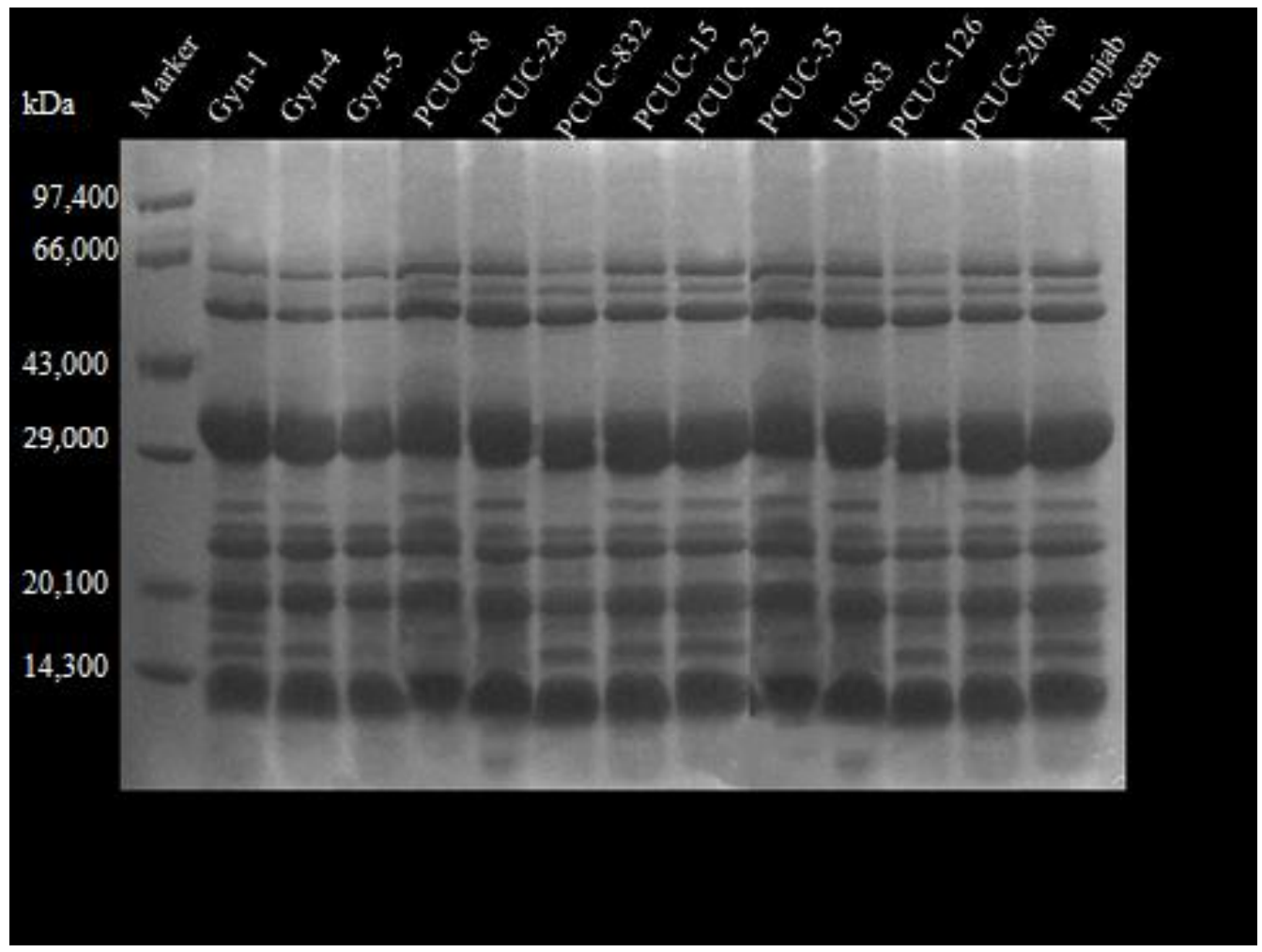


Fig.2 UPGMA dendrogram of protein profile of gynoecious and monoecious genotype cucumber

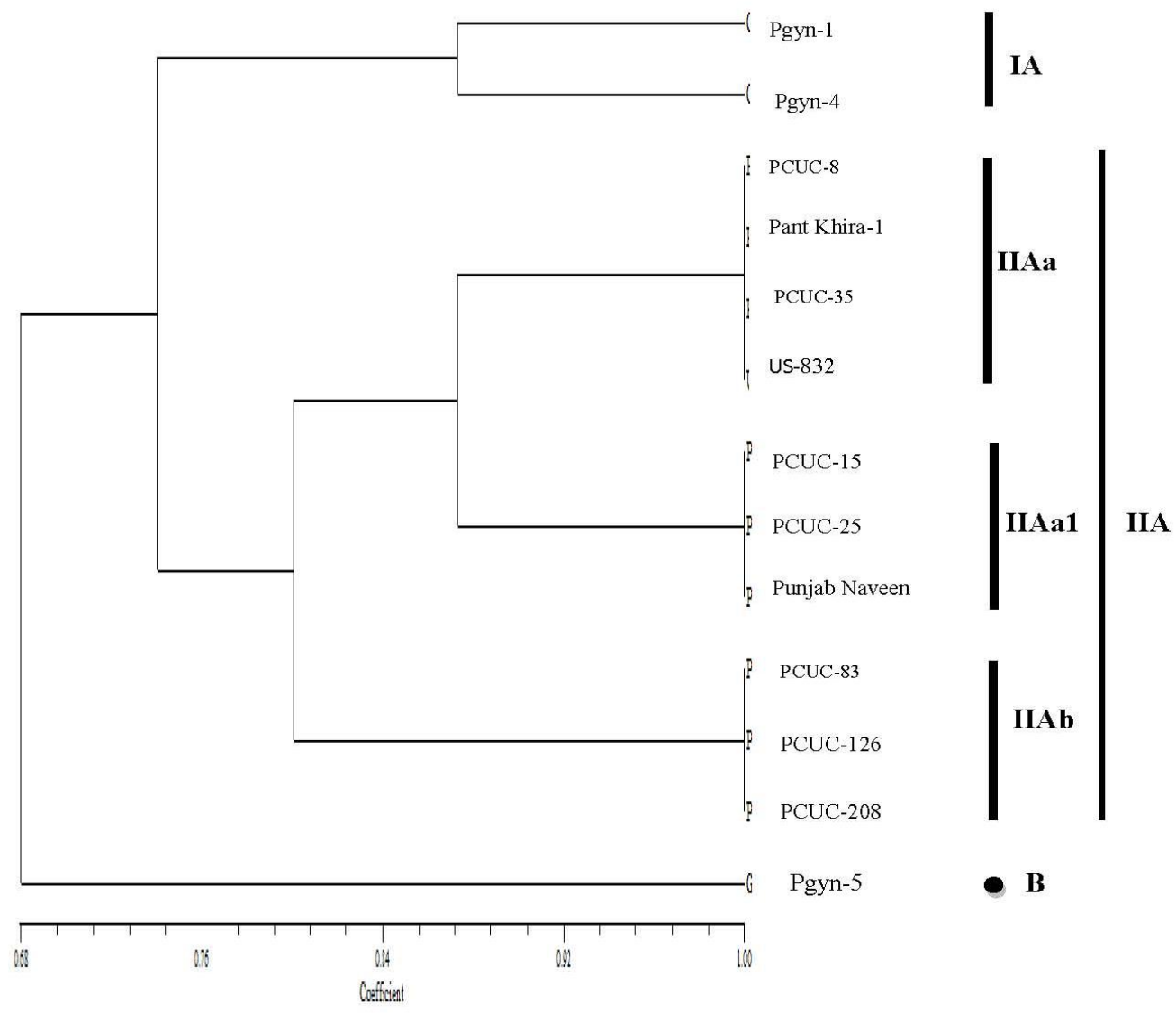

Table.1 List of cucumber genotypes and their sources

\begin{tabular}{|l|l|l|l|}
\hline Sl. No. & Germplasm Line & Nature & Source \\
\hline 1. & Pgyn-1 & Gynoecious & Pantnagar \\
\hline 2. & Pgyn-4 & Gynoecious & Pantnagar \\
\hline 3. & Pgyn-5 & Gynoecious & Pantnagar \\
\hline 4. & PCUC-8 & Monoecious & Pantnagar \\
\hline 5. & Pant Khira-1 & Monoecious & Pantnagar \\
\hline 6. & PCUC-83 & Monoecious & Pantnagar \\
\hline 7. & PCUC-126 & Monoecious & Pantnagar \\
\hline 8. & PCUC-208 & Monoecious & Pantnagar \\
\hline 9. & PCUC-15 & Monoecious & Pantnagar \\
\hline 10. & PCUC-25 & Monoecious & Pantnagar \\
\hline 11. & PCUC-35 & Monoecious & Pantnagar \\
\hline 12. & US-832 & Monoecious & UAS, Bangalore \\
\hline 13. & Punjab Naveen & Monoecious & PAU, Ludhiana \\
\hline
\end{tabular}


Table.2 Similarity matrix of protein profile in genotypes of cucumber

\begin{tabular}{|l|l|l|l|l|l|l|l|l|l|l|l|l|l|}
\hline & $\begin{array}{l}\text { Pgyn- } \\
\mathbf{1}\end{array}$ & $\begin{array}{l}\text { Pgyn- } \\
\mathbf{4}\end{array}$ & $\begin{array}{l}\text { Pgyn- } \\
\mathbf{5}\end{array}$ & $\begin{array}{l}\text { PCUC- } \\
\mathbf{8}\end{array}$ & $\begin{array}{l}\text { Pant } \\
\text { Khira-1 }\end{array}$ & $\begin{array}{l}\text { US- } \\
\mathbf{8 3 2}\end{array}$ & $\begin{array}{l}\text { PCUC- } \\
\mathbf{1 5}\end{array}$ & $\begin{array}{l}\text { PCUC- } \\
\mathbf{2 5}\end{array}$ & $\begin{array}{l}\text { PCUC- } \\
\mathbf{3 5}\end{array}$ & $\begin{array}{l}\text { PCUC- } \\
\mathbf{8 3}\end{array}$ & $\begin{array}{l}\text { PCUC- } \\
\mathbf{1 2 6}\end{array}$ & $\begin{array}{l}\text { PCUC- } \\
\mathbf{2 0 8}\end{array}$ & $\begin{array}{l}\text { Punjab } \\
\text { Naveen }\end{array}$ \\
\hline Pgyn-1 & 1.000 & & & & & & & & & & & \\
\hline Pgyn-4 & 0.875 & 1.000 & & & & & & & & & & \\
\hline Pgnn-5 & 0.625 & 0.714 & 1.000 & & & & & & & & & \\
\hline PCUC-8 & 0.667 & 0.750 & 0.714 & 1.000 & & & & & & & & \\
\hline Pant Khira 1 & 0.667 & 0.750 & 0.714 & 1.000 & 1.000 & & & & & & & \\
\hline PCUC832 & 0.667 & 0.750 & 0.714 & 0.750 & 0.750 & 1.000 & & & & & & \\
\hline PCUC-15 & 0.778 & 0.875 & 0.625 & 0.875 & 0.875 & 0.875 & 1.000 & & & & & \\
\hline PCUC-25 & 0.778 & 0.875 & 0.625 & 0.875 & 0.875 & 0.875 & 1.000 & 1.000 & & & & \\
\hline PCUC-35 & 0.667 & 0.750 & 0.714 & 1.000 & 1.000 & 0.750 & 0.875 & 0.875 & 1.000 & & & \\
\hline PCUC-83 & 0.667 & 0.750 & 0.714 & 1.000 & 1.000 & 0.750 & 0.875 & 0.875 & 1.000 & 1.000 & & \\
\hline PCUC-126 & 0.667 & 0.750 & 0.714 & 0.750 & 0.750 & 1.000 & 0.875 & 0.875 & 0.750 & 0.750 & 1.000 & & \\
\hline PCUC-208 & 0.667 & 0.750 & 0.714 & 0.750 & 0.750 & 1.000 & 0.875 & 0.875 & 0.750 & 0.750 & 1.000 & 1.000 & \\
\hline Punjab Naveen & 0.778 & 0.875 & 0.625 & 0.875 & 0.875 & 0.875 & 1.000 & 1.000 & 0.875 & 0.875 & 0.875 & 0.875 & 1.000 \\
\hline
\end{tabular}

The differences in banding patterns were either with total number of bands present, location of bands and intensity of bands or it can even be the presence or absence of four categories of bands namely dense, medium, light, and faint. The overall differential banding pattern of seed proteins indicated qualitative and quantitative variations among the different genotypes. These observations suggested that with electrophoretic differences in protein banding pattern of different genotypes, specific varieties were identified with the presence or absence of a specific position of band and also the intensity of band, which could be used as genetic marker. Singh and Ram (2005) also reported similar type of banding and characterization in thirty lines of cucumber by SDS-PAGE. Present study results were also in line with Singh et al., (2010). They studied the biochemical characterization of total fifteen genotypes including four parthenocarpic gynoecoius cucumber lines and their three hybrids, four monoecious varieties (Cucumis sativus L.), three wild relatives (Cucumis sativus var. hardwickii) and a backcross which were subjected to seed protein analysis through SDS-PAGE. They observed different banding pattern in their study. However, differences among genotypes for darkness and thickness of protein bands were also evident. Ladizinsky and Hymowitz (1979) reported such variation as the commonly reported ones, suggesting that the formation of many of the bands in the seed protein profile are under control of quantitative gene system and such variation may be due to lack of separation of several proteins having similar migration rates on the gels.

\section{Similarity index (SI) and UPGMA cluster analysis}

The variation in number and position of bands was expressed by similarity index. The method was used by Vaughan and Denford (1968), which expresses the variation in the banding pattern between two gels.

This similarity index was used for analysis of parental genotypes in cucumber. The similarity index value ranged from $62 \%$ to $100 \%$ among all the genotypes (Table 2).

The genotype Pgyn-1 showed least similarity $68 \%$ with other gynoecious genotypes Pgyn1, Pgyn-4 and other monoecious genotypes. On the basis of protein profile of thirteen cucumber genotypes the un-weighted pair group method using arithmetic average 
(UPGMA) analysis was done. The dendrogram is presented in Figure 2. The genotypes were clustered into two major clusters (A and B) with $68 \%$ similarity among them. Cluster A comprised 12 genotypes and cluster B comprised only one Pgyn-1 genotype.

Cluster A was further subdivided into two sub-clusters IA and IIA with $72 \%$ similarity. Sub-cluster IA comprised two gynoecious genotypes with $87 \%$ similarity. The cluster IIA comprised all the ten monoecious genotypes and was further divided into two with $80 \%$ similarity. IIA was again forked into two small groups IIAa and IIAb with $87 \%$ similarity.

In IIAa four monoecious genotypes PCUC-8, Pant Khira-1 and PCUC-35 and PCUC-83 were present with $100 \%$ similarity among each. IIAb had three genotypes PCUC-15 PCUC-25 and Punjab Naveen with 100\% similarity among each. IIAc was divided into minor cluster with $100 \%$ similarity to each other which comprised three monoecious genotypes US-832, PCUC-126 and PCUC208. Singh and Ram (2000) classified 19 cucumber germplasm in eight different groups. Singh and Ram (2005) reported that the protein bands in cucurbits were genera specific. Singh et al., (2010) categorized fifteen genotypes of cucumber into two major groups.

Seed storage protein profiles could be useful marker for genotype identification and diversity analysis (between and within Cucumis species). Characterization on the basis of proteins and selection of desirable lines/genotypes is great importance for breeders. Precise differentiation in protein banding patterns is possible on the basis of the presence or absence of unique polypeptides, and the creation of matrices for statistical analyses. Their clustering allows the ranging of genotypes in either closer or distinct groups, which could also be used for the breeder's needs, as well as in the seed industry for identification and selection of desirable cucumber genotypes.

\section{References}

Agrawal, P. K. 1985. Field plot test for assessing genetic purity in hybrid cotton, Seed Tech News, 15(3): 1-5.

Ahl, P., Cornu, A. And Gianninazzi, S. 1982. Soluble proteins as genetic markers in studies of resistance and phylogeny in Nicotiana. Phytopathology 72: 80-85.

Anonymous. 1994 a. UPOV guidelines for the conduct of test for DUS-Wheat (Triticum aestivum) UPOV, TG/3/11.

Anonymous. 1994 b. UPOV guidelines for the conduct of test for DUS-barley (Hordeum vulgare) Revised document UPOV, $\mathrm{TG} / 2 / 5$.

Dane, F. 1983. Cucurbits, In: Isozymes in Plant Genetics and Breeding, Part B. C.D. Tanksley and T.J. Orton (Eds.). Elsevier Science Publishers, Amsterdam, pp. 369380.

Doyle, J J and Doyle, J L. 1987. A rapid DNA isolation procedure for small quantities of fresh leaf tissue. Phytochemistry Bulletin 19:11-15.

Doyle, J.J. and J.L. Doyle. 1987. A rapid DNA isolation procedure for small quantities of fresh leaf tissue. Phytochemistry Bulletin 19: 11-15.

Gepts, P. 1990. Genetic diversity of seed storage proteins in plants. In: A.H.D. Brown, M.T. Clegg, A.L. Kahler and B.S. Weir (Eds.). Plant Population Genetics, Breeding and Genetic Resources, Sunderland, Sinauer Assoc. members of the subfamily Papilionoideae. Journal of Agronomy and Crop Science.

International Seed Testing Association. 1996. International Rules for Seed Testing, Seed Science and Technology 24, Supplement $1-228$. 
Iqbal S H, Ghafoor A and Ayub N. 2005. Relationship between SDS-PAGE markers and Ascochyta blight in chickpea. Pakistan Journal of Botany 37: 87-96.

Javaid A, Ghafoor A and Anwar R. 2004. Seed storage protein electrophoresis in groundnut for evaluating genetic diversity. Pakistan Journal of Botany 30 (1): $25-29$.

Jeffrey, C. 2005. A new system of Cucurbitaceae. Bot. Zhurn. 90: 332-335.

Johari R P, Metha S L and Naik M S. 1977. Changes in soluble protein and isoenzymes in developing sorghum grains. Crop Sci. 46: 409-411.

Knerr, I D, Meglic, V and Stans, J E. 1995. Fourth malate dehydrogenase (MDH) locus in cucumber. Hort. Sci., 30 (1): 118-119.

Laemmli, U.K. 1970. Cleavage of structural proteins during the assembly of the head of bacteriophage T4, Nature 227: 680685 .

Landizinsky G and Hymowitz T. 1979. Seed protein electrophoresis in taxonomic and evolutionary studies. Theoretical and Applied Genetics 54: 145-51.

Larsen A L and Benson W C. 1970. Varietyspecific variants of oxidative enzymes from soybean seed. Crop Sci. 10: $493-$ 495.

Protection of Plant Varieties and Farmers' Rights Act. 2001. http://www. plantauthortiy.gov.in.

Sammour R. H. 1987. Electrophoretic and serological studies of the seed proteins of some members of the subfamily Papilionoideae. Journal of Agronomy and Crop Science. 159: 282-286.
Shaefer, H and Renner S S. 2011. A Cucurbitaceae. Families and genera of vascular plants. Springer Verlag, Berlin (ed by Kubitzki). 10: 112-174.

Singh, A. and Ram, H H. 2005. Characterization of germplasm lines of cucumber (Cucumis sativus L.) through seed protein profiles. Veg. Sci. 32(2):117119.

Singh, D K and Ram, Hari Har. 2000. Characterization of indigenous germplasm lines of cucumber (Cucumi ssativus L.) through SDS-PAGE. Veg. Sci. 28 (1): 22-23.

Singh, D K, Padiyar, S. and Choudhary, H. 2010. Biochemical characterization of parthenocarpic gynoecious cucumber lines, hybrids, monoecious varieties and wild relatives. Indian J. of Hort. 67(3): 343-347.

Smith J S C and Smith O S. 1992. Fingerprinting crop varieties. Adv. Agron. 47: 85-140.

Smith, J.S.C. and Smith, O.S. 1992. Fingerprinting in varieties. Advances Agron. 47: 85-140.

Ullah I, Ahmad Khan I, Ahmad H, Sul-Gafoor S Gul, Muhammad I and Ilyas M. 2010. Seed storage protein profile of rice varieties commonly grown in Pakistan. Asian Journal of Agricultural Sciences 2 (4): 120-123.

Vaughan, J.G. and Denford, K.E. 1968. An acrylamide gel electrophoretic study of the seed proteins of Brassica and Sinapsis species with special reference to their taxonomic value. J. Exp. Bot. 19: 724732 .

Wilkinson, J F. and Beard, J. B. 1972. Electrophoretic identification of cultivars. Crop Sci. 12: 833-834.

\section{How to cite this article:}

Shailaja Punetha, Basavaraj Makanur, Deepali Tewari and Parul Punetha. 2018. Electrophoretic Characterization of Gynoecious and Monoecious Cucumber (Cucumis sativus L.) Genotypes Based on Seed Protein Profiles. Int.J.Curr.Microbiol.App.Sci. 7(10): 3021-3029. doi: https://doi.org/10.20546/ijcmas.2018.710.352 